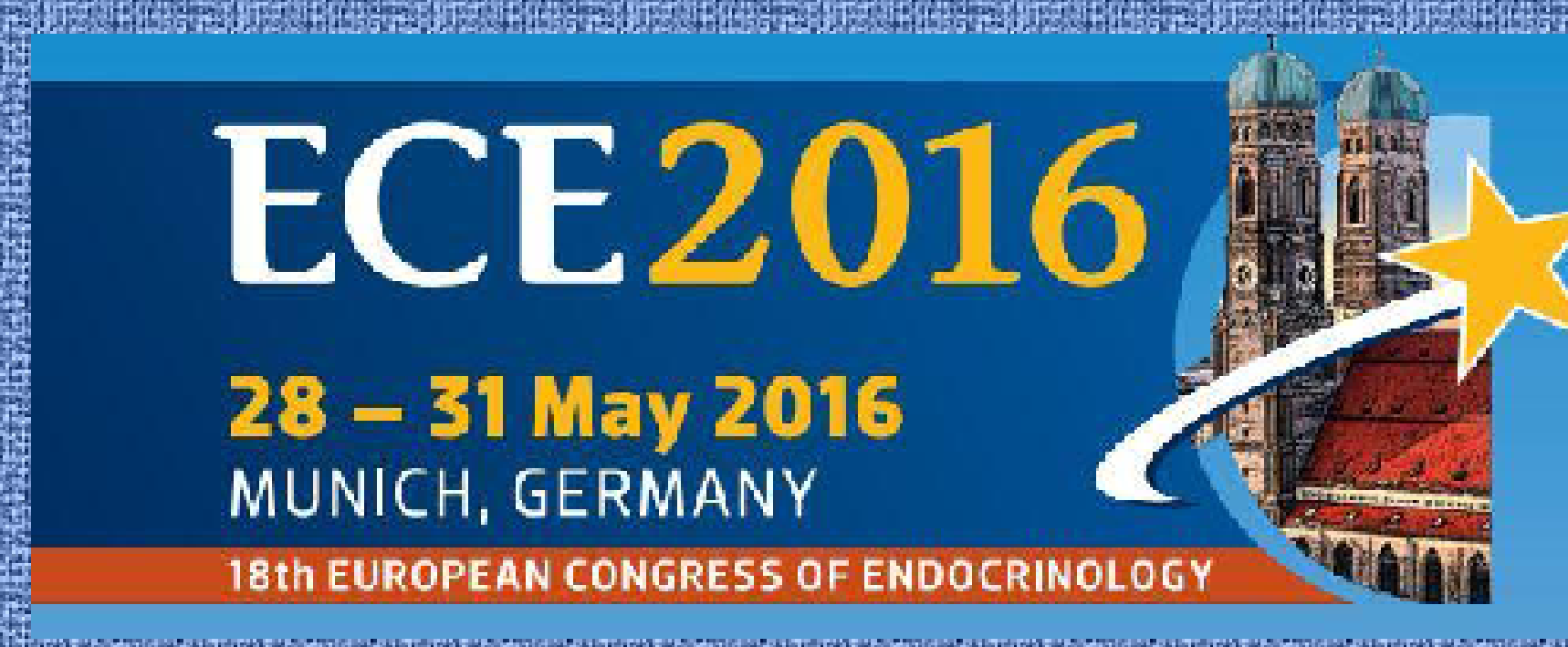

\title{
ASSESSMENT OF QUALITY OF LIFE IN ANEMIC AND NON-ANEMIC PATIENTS WITH EARLY STAGES OF DIABETIC NEPHROPATHY
}

\author{
I. Pchelin, A. Shishkin, M. Erman, O. Vasilkova \\ St. Petersburg State University, Department of Faculty Therapy. St. Petersburg, Russia \\ Gomel State Medical University. Gomel, Belarus
}

\section{Introduction}

Anemia occurs early and predicts high risk of death in patients with diabetic nephropathy. Diabetic patients with anemia are at increased risk of adverse outcomes from diabetic nephropathy, neuropathy and cardiovascular disease.

In patients with early stages of diabetic nephropathy anemia may result from various factors including:

- erythropoietin deficiency,

- iron, vitamin B12 and folate deficiencies,

- inflammation,

- autoimmune disorders,

- hemolysis,

- adverse effects of some drugs and others.

The impact of anemia, erythropoietin deficiency and inflammation on the impaired quality of life at early stages of diabetic nephropathy is unknown

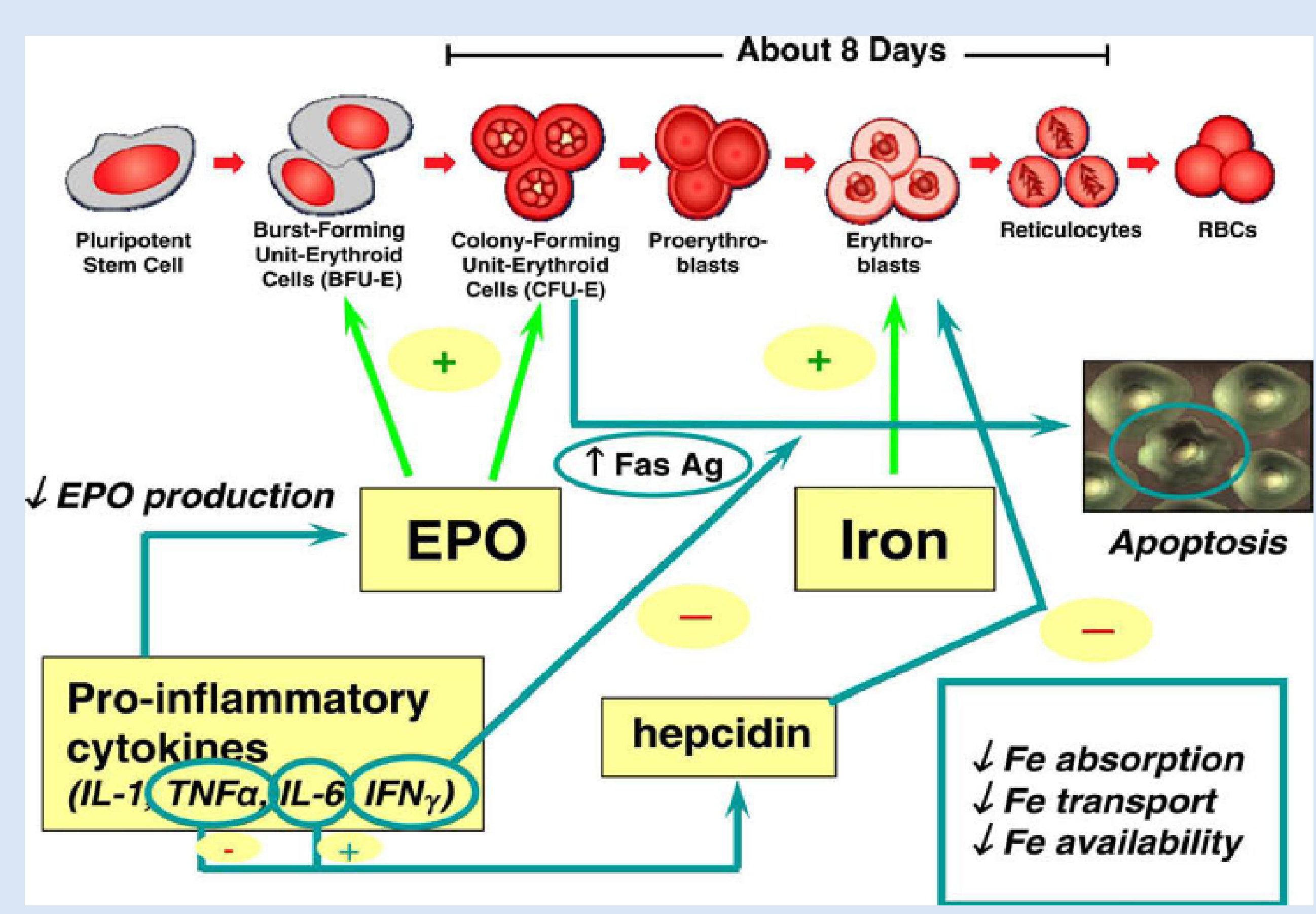

Figure 1. Erythropoiesis in chronic kidney disease (I. Macdougall, 2009)

$\mathrm{Ag}$, antigen; EPO, erythropoietin; Fe, iron; IFN, interferon; IL, interleukin; RBCs, red blood cells; TNF, tumor necrosis factor

\section{Aim}

The aim of this study was to assess the influence of anemia on the quality of life of patients with early stages of diabetic nephropathy.

\section{Patients and methods}

We investigated 95 anemic and 32 nonanemic patients with type 2 diabetes mellitus and early stages of diabetic nephropathy (CKD stages 1-3)

Anemia was defined according to $\mathrm{WHO}$ criteria. Anemic patients were divided into groups 1, 2 and 3 according to the stage of CKD

Patients' quality of life was assessed with SF36 health survey.

Student's t-test was used for statistical analysis.

\section{Results}

As compared to patients without anemia subjects from groups 1, 2 and 3 had lower scores of physical role functioning $(49,8 \pm 4,2$ vs. $25,0 \pm 7,2,34,8 \pm 3,0$ and $12,5 \pm 9,6$, respectively, $p<0,05)$ and emotional role functioning $(57,9 \pm 5,2$ vs. $33,6 \pm 5,9,39,8 \pm 3,5$ and $33,5 \pm 6,2$, respectively, $p<0,05)$.

Groups 1 and 2 had no significant differences in other SF-36 sections with the non-anemic group.

Patients in group 3 had lower scores of general health perceptions, physical functioning, bodily pain, vitality and mental health than patients in the non-anemic group: $27,4 \pm 4,1$ vs. $43,3 \pm 3,2,25,0 \pm 4,2$ vs. $65,9 \pm 6,9$ $43,7 \pm 3,3$ vs. $60,3 \pm 3,9,32,5 \pm 5,8$ vs. $49,6 \pm 4,2$ and $38,8 \pm 3,5$ vs. $57,8 \pm 2,8$, respectively $(p<0,05)$

Social role functioning was similar in all four groups.

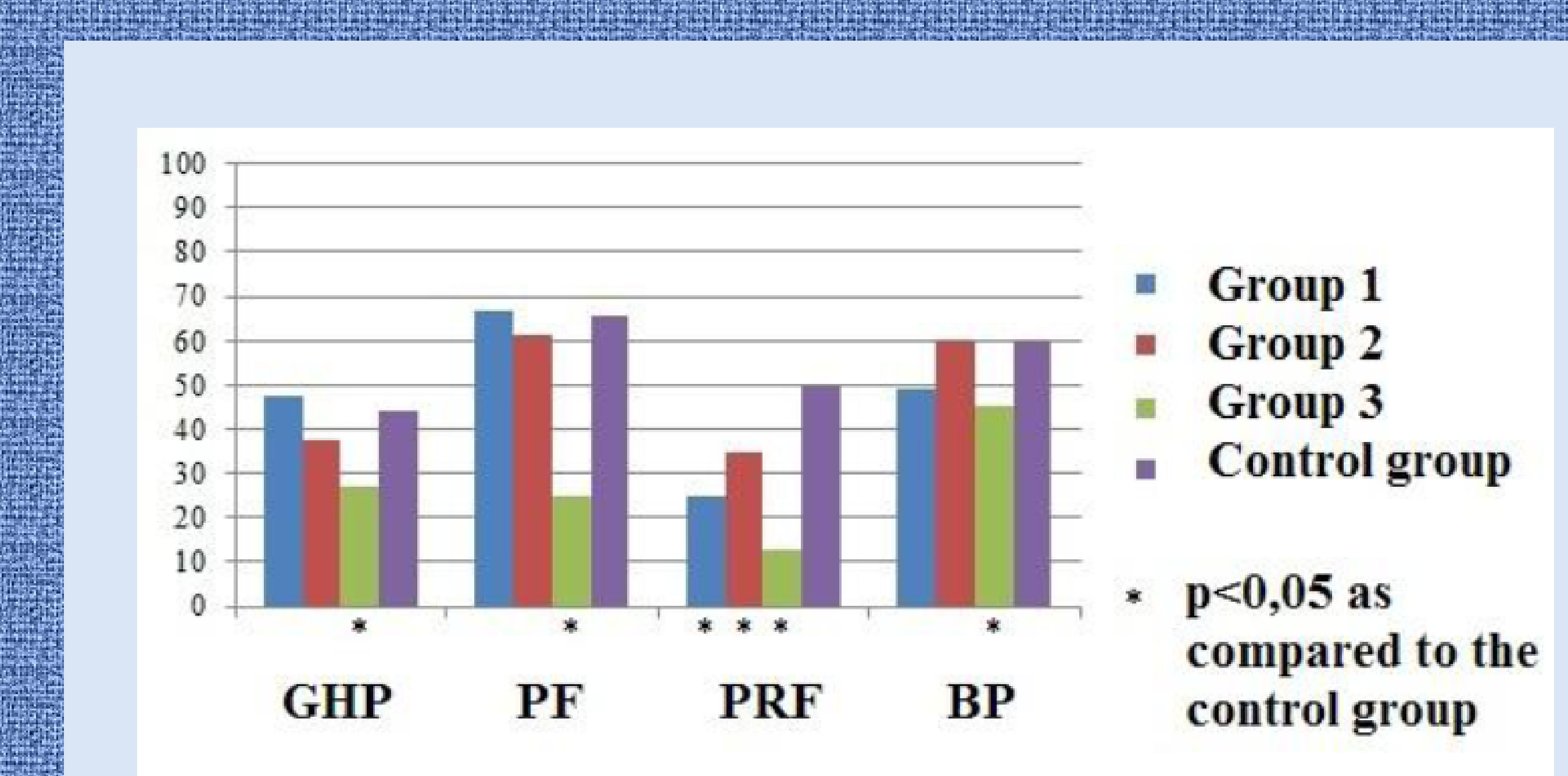

Figure 2. Physical components of quality of life GHP - general health perceptions, PF - physical functioning, PRF - physical role functioning, BP - bodily pain

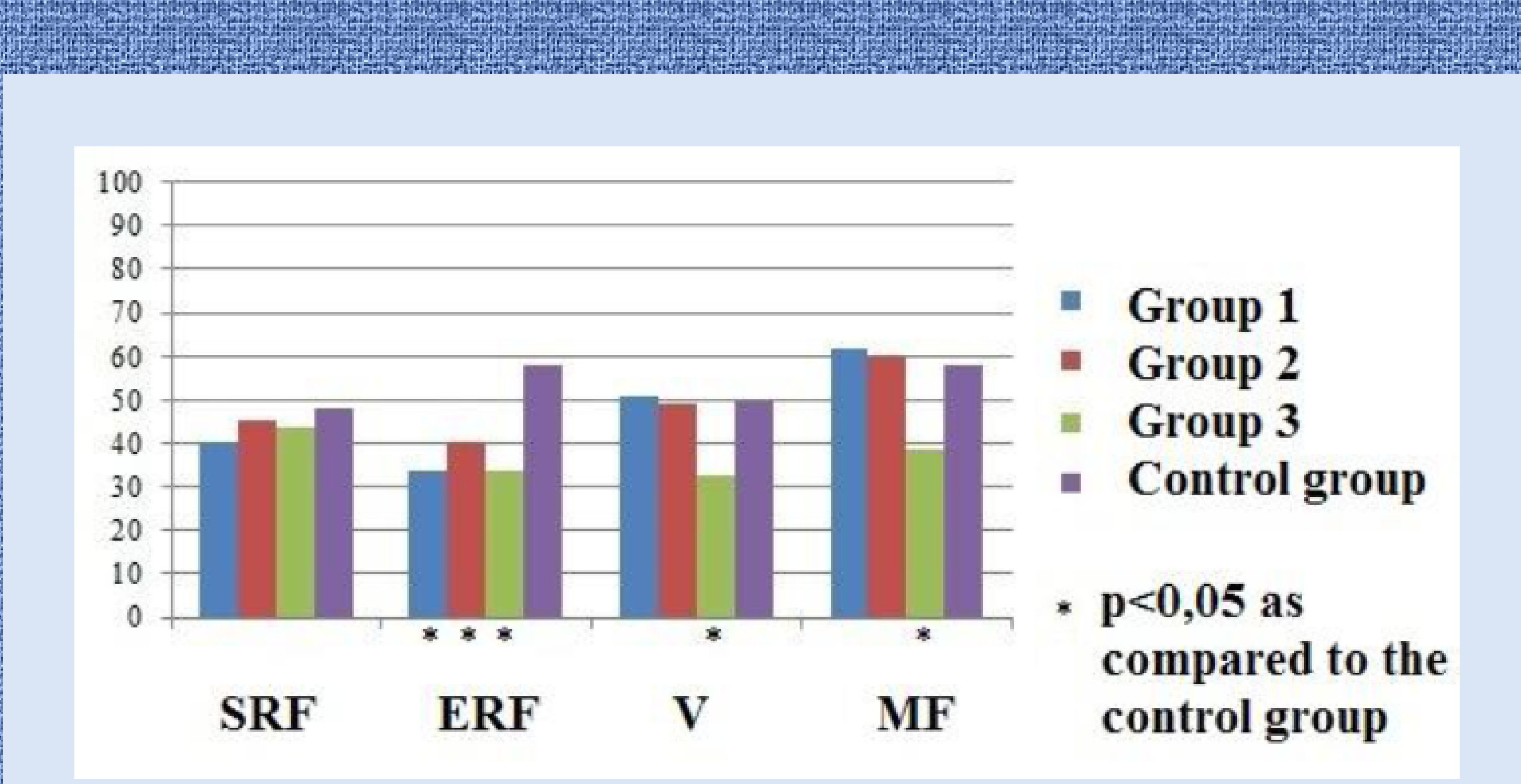

Figure 3. Psychological components of quality of life

SRF - social role functioning, ERF - emotional role functioning $\checkmark$ - vitality, MF - mental functioning

\section{Conclusion}

The results of the study suggest that anemia has a substantial influence on patients' quality of life in settings of early diabetic nephropathy. Physical role functioning and emotional role functioning are affected by anemia irrespective of the CKD stage.

\section{References}

1. Joss N., Patel R., Paterson K. et al. Anaemia is common and predicts mortality in diabetic nephropathy // QJM. 2007. Vol. 100. P. 641-647. 2. Lankhorst C. E., Wish J. B. Anemia in renal disease: Diagnosis and management // Blood Rev. 2010. Vol. 24. P. 39-47.

3. McGill J. B., Bell D. S. H. Anemia and the role of erythropoietin in diabetes // J. Diabetes Complications. 2006. Vol. 20. P. 262-272.

\section{Contact Information}

St. Petersburg State University

The Faculty of Medicine

Department of Faculty Therapy

Tel.: +7 9213614700

E-mail: i.pchelin@mail.ru

http://eng.spbu.ru/

\section{Declaration of interest}

The authors declare that there is no conflict of interest that could be perceived as prejudicing the impartiality of the research project.

\section{Funding}

The study was supported by the President Grant for Government Support of Young Russian Scientists MK-5632.2015.7. 